\title{
A Study of the Diastolic Flow Velocity Profile of the Clinically Uncomplicated Mitral Porcine Bioprosthesis Using an Echo-Doppler Technique
}

\author{
Veena Raizada, M.D., Thomas W. Hoyt, M.D., \\ Sue Corlew, and Jonathan Abrams, M.D.
}

\section{SUMMARY}

Pulsed Doppler echocardiography was performed in 17 subjects who had clinically uncomplicated porcine bioprosthesis in the mitral position. A positive initial diastolic flow wave was present in all patients; end-diastolic A waves were seen in the sinus rhythm of every patient. The peak of the diastolic wave was delayed when compared with the normals in our laboratory. This wave had clearly demarcated ascending, mid- and descending segments. When contrasted with normal subjects, the slope of the diastolic wave was mildly reduced in all patients. Fine to coarse indentations on the descending and mid-segments were seen in $15 / 17(88 \%)$ of the patients. We conclude that the diastolic flow profile of the clinically uncomplicated mitral bioprosthesis resembles mild mitral stenosis. Reduced orifice size and/or the physical properties of the bioprosthesis are the likely mechanisms for these alterations.

\section{Additional Indexing Words:}

Mitral bioprosthesis

Diastolic flow

Pulsed Doppler echocardiography

7 HE dynamic characteristics of the currently available cardiac valves are 1 of great importance in determining the relative merit of each prosthesis. Pressure and flow studies by cardiac catheterization of the normal porcine bioprosthesis in the mitral position in human subjects have shown this prosthesis to be mildly obstructive to diastolic filling of the left ventricle. ${ }^{1-5)}$ The purpose of this study was to non-invasively characterize the blood flow dynamics of the normally functioning mitral porcine bioprosthesis by pulsed

From the Division of Cardiology, Department of Medicine, University of New Mexico School of Medicine and the Division of Thoracic Surgery, Presbyterian Hospital Center, Albuquerque, New Mexico 87131, U.S.A.

Presented in part at the VIII World Congress of Cardiology, Tokyo, Japan, September, 1978 and the International Cardiovascular Congress II, Scottsdale, Arizona, February, 1979.

Address for reprint: Veena Raizada, M.D., Division of Cardiology, Department of Medicine, University of New Mexico School of Medicine, Albuquerque, New Mexico 87131, U.S.A.

Received for publication November 25, 1981. 
Doppler echocardiography. Once the normal Doppler flow profile for the porcine heterograft is defined, patients with suspected prosthetic valve malfunction can be evaluated by this noninvasive technique as a prelude to possible hemodynamic investigation.

\section{Materials ANd Methods}

The study group was comprised of 17 patients (12 women and 5 men), aged 16-60 years, who had undergone mitral valve replacement with a porcine bioprosthesis (size $27-33 \mathrm{~mm}$ ); 11 were in atrial fibrillation and 6 in sinus rhythm. The interval from valve replacement to the present study averaged 1 year, with a range of 6 months to three and one-half years. All patients were asymptomatic (New York Heart Association Class I) at the time of the study. Prosthetic valve and left ventricular function was normal as determined by $\mathrm{M}$-mode and two-dimensional echocardiography, ${ }^{6)-9)}$ and hence, none of these patients were subjected to a repeat cardiac catheterization.

We used a commercially available (Advanced Technology Laboratories, Model 500A) single crystal unidimensional blood flowmeter. This instrument provides a simultaneous M-mode display for identification of intracardiac structures, position of the sample volume in relation to these structures, and spectral and analogue Doppler flow signals. A 3 megahertz piezoelectric transducer was oppositioned at the left ventricular apex and its direction was modified in order to orient the ultrasonic beam parallel to the axis of the prosthetic sewing ring, approximating the axis of the beam parallel to the anatomical apex-base axis of the heart. All studies were performed with the patients in the left decubitus position. The position of the sample volume was adjusted within the mitral bioprosthesis until clear Doppler signals of the mitral flow were obtained.

\section{RESULTS}

The Doppler echocardiograms were analyzed for the presence of positive or negative diastolic and end-diastolic waves. The diastolic flow waves were analyzed for the presence of fine or coarse indentations on the ascending, midand descending scgments; these slopes were categorized as rapid or slow.

Normal pattern of blood flow at the mitral orifice: The following is a brief description of the blood flow profile at the mitral orifice, obtained from healthy subjects in our laboratory and as described previously by other investigators using intracardiac ${ }^{10), 11)}$ and transcutaneous Doppler flowmeters. ${ }^{12), 13)}$ The normal diastolic flow profile provides a comparative basis for patients with a 


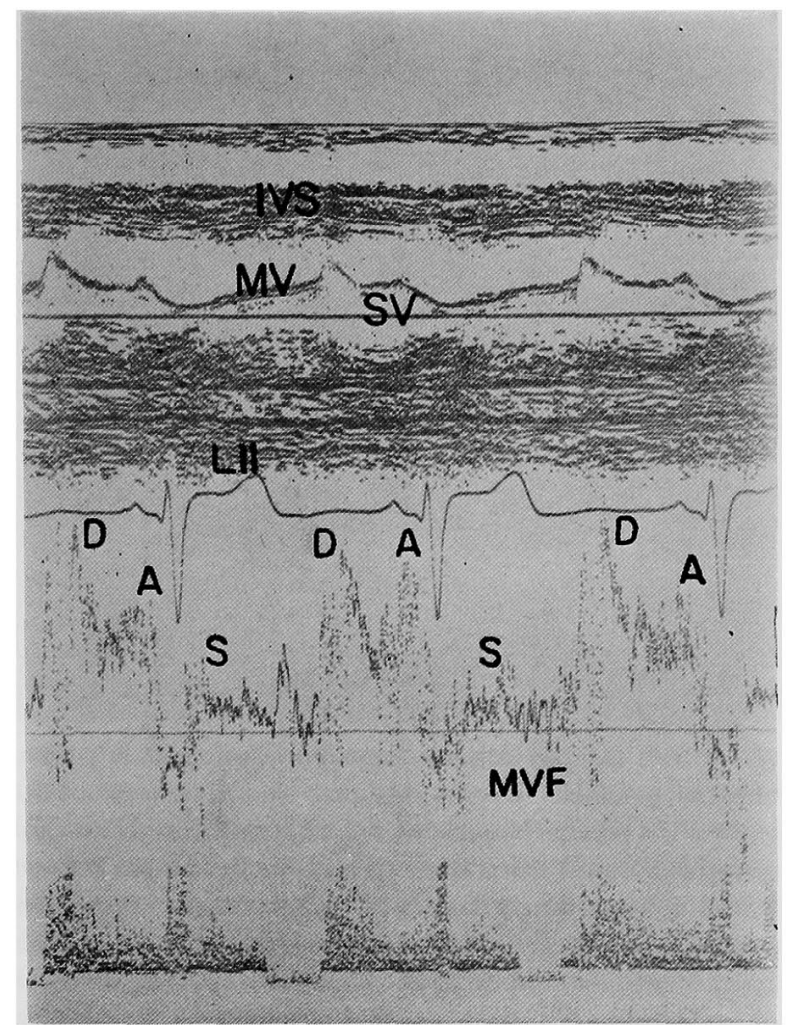

Fig. 1. Mitral valve flow velocity pattern in a normal subject, as recorded in our laboratory. Top to bottom: Mitral valve echocardiogram with the sample volume positioned within the mitral orifice, lead II of the electrocardiogram and diastolic flow wave (D). The onset of the diastolic wave occurs immediately following the inscription of the $\mathrm{T}$ wave on the electrocardiogram. The slope of the ascending segment is rapid and the peak of the $\mathrm{D}$ occurs during early to mid-diastole. The indentations on the $\mathrm{D}$ are absent. The A wave occurs during end-diastole, and follows the inscription on the $\mathrm{P}$ wave; its height is equal to or much less than the $D$ wave.

$\mathrm{A}=$ end-diastolic wave; $\mathrm{D}=$ diastolic flow wave; IVS = interventricularseptum; L II = lead II of the electrocardiogram; $M V=$ mitral valve; $M V F=$ mitral valve flow; $\mathrm{S}=$ systolic wave; $\mathrm{SV}=$ sample volume.

mitral porcine bioprosthesis.

The diastolic flow profile of a normal mitral valve is characterized by a large diastolic wave (D), followed by a smaller and shorter end-diastolic wave (A); the latter coincides with the atrial contraction (Fig. 1). 10)-13) The A wave reaches its peak $160-200 \mathrm{msec}$ after the inscription of the $\mathrm{P}$ wave. The diastolic wave is larger than the $\mathrm{A}$ wave at normal or slow heart rates. The ascending segment of the diastolic wave is rapid and begins immediately after the second heart sound. The peak of the diastolic wave occurs in early to mid-diastole, 130-200 msec after the aortic component of the second heart 


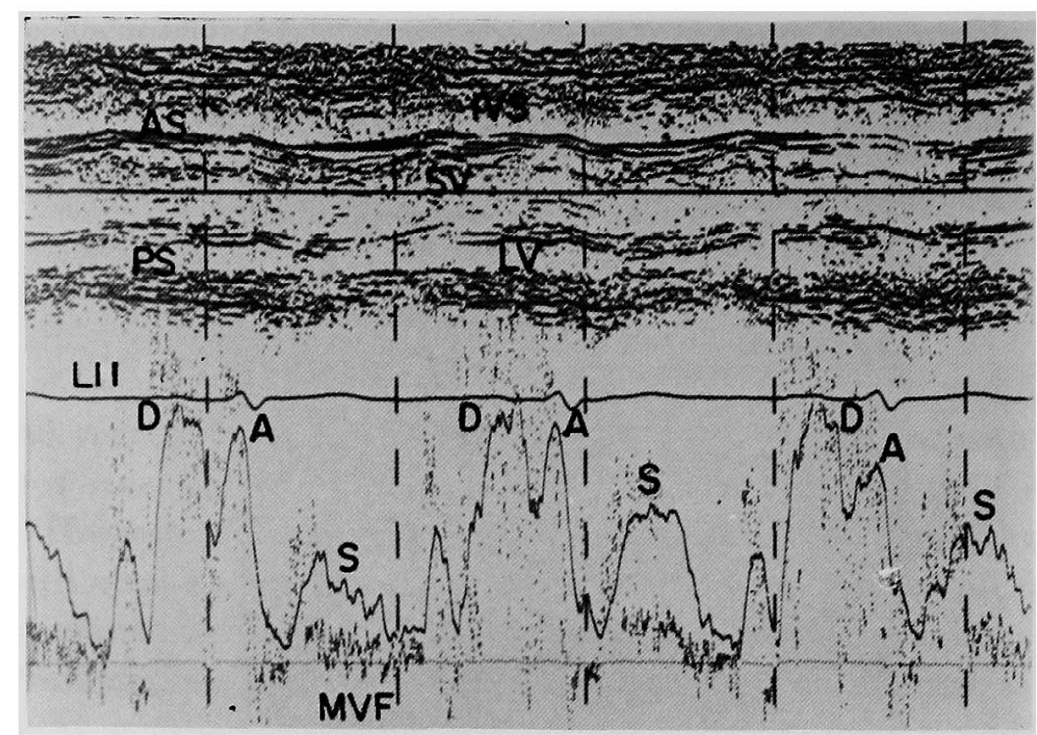

Fig. 2. Pulsed Doppler echocardiographic findings in a patient with a porcine mitral bioprosthesis in sinus rhythm. Top to bottom: Mitral valve echocardiogram of a porcine bioprosthesis; L II of a 12 lead electrocardiogram; and transprosthetic mitral valve flow. The Doppler sample volume is positioned between the stent/ring echoes of the bioprosthesis. Spectral and analogue flow records from the mitral bioprosthesis demonstrate a marked delay in the occurrence of the peak of the diastolic flow wave, with the peak occurring in late diastole. A relatively short proportion of diastole is occupied by the diastolic flow. In addition, the ascending and descending segments of the diastolic waves are normal; fine indentations are seen during the mid-segment. An enddiastolic wave (A) and a positive systolic wave (S) are seen.

$\mathrm{A}=$ end-diastolic wave; $\mathrm{AS}-\mathrm{PS}=$ anterior and posterior stent/ring echoes; $\mathrm{D}=$ positive diastolic wave IVS = interventricular septum; L II = lead II of the electrocardiogram; $\mathrm{LV}=$ left ventricle; $\mathrm{MVF}=$ mitral valve flow; $\mathrm{S}=$ systolic wave; $\mathrm{SV}=$ sample volume.

sound. The descending segment of this wave is produced by a rapid deceleration of diastolic flow which precedes mitral valve closure.

Patterns of mitral flow velocity in patients with an uncomplicated mitral porcine bioprosthesis: A positive initial diastolic flow wave (D), was present in all 17 patients and an end-diastolic A wave was seen only in patients in sinus rhythm (Fig. 2). The height of the A wave was equal to or slightly less than the peak of the initial diastolic wave; the amplitude of A wave did not exceed that of the diastolic wave in any patients. The time interval from the end of the $\mathrm{T}$ wave to the peak of the diastolic wave ranged from 250-360 msec (mean $306 \mathrm{msec}$ ). The peak of the diastolic wave was delayed when compared with normal subjects in our laboratory; it occurred earlier in diastole during long and later in diastole during short cycle lengths (Fig. 3). This wave had ascending, midand descending segments. When contrasted with normal subjects, the slope 


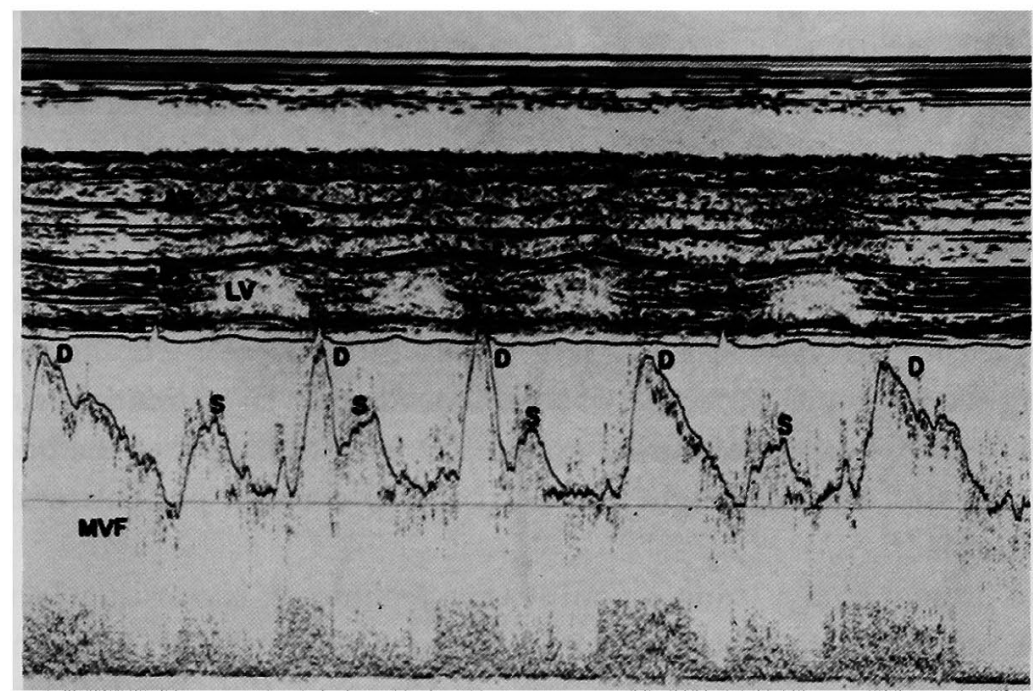

Fig. 3. Pulsed Doppler echocardiographic findings in a patient with a mitral porcine bioprosthesis in atrial fibrillation. The slope of the ascending segment of the diastolic flow wave (D) is normal to mildly reduced. The peak of the D occurs earlier during long, and later during short R-R cycles; it coincides with electrical systole during short diastoles. Fine to coarse indentations on the mid and the descending segments are also seen.

IVS=interventricular septum; SV=sample volume; AS-PS=anterior and posterior stent/ring echoes; $\mathrm{LV}=$ left ventricle; $\mathrm{D}=$ diastolic wave; $\mathrm{MVF}=$ mitral valve flow.

of the ascending segment of the diastolic wave was mildly reduced in all patients with bioprosthetic mitral valves. In addition, in atrial fibrillation, deceleration of the diastolic flow wave to the baseline occurred earlier in long and later during short diastoles. During short cycle lengths $(=\mid<800 \mathrm{msec})$, diastolic flow continued bcyond end-diastole, coinciding with the inscription of the QRS (Fig. 3). Fine to coarse indentations on the mid- or descending segments were seen in 15 of $17(88 \%)$, and additionally on the ascending segment in 2 patients.

The abnormalities of mitral valve flow were unrelated to the size of the prosthesis and the duration of the follow-up period.

\section{Discussion}

Although its limitations are recognized, ${ }^{12), 13\}}$ the pulsed Doppler flow analysis technique with simultaneous M-mode echocardiography provides a unique method for studying mitral blood flow characteristics. It has been shown to be a reliable method for assessing the severity of mitral stenosis, ${ }^{13), 14)}$ 
Kalmanson et al, using a transcutaneous pulsed Doppler flowmeter, described abnormalities of the initial (D) and end-diastolic (A) flow waves in patients with isolated mitral stenosis. ${ }^{13), 14}$ These changes consisted of indentations on the ascending, mid-, and descending segments of the large initial diastolic wave; the earlier the onset and greater the amplitude of the indentations, the more severe the stenosis. The slope of the ascending segment and the timing of its peak were normal or only slightly delayed in mild mitral stenosis; with more severe mitral valve obstruction, indentations were seen earlier on the ascending segment and the slope was more gradual. In patients in sinus rhythm, the A wave amplitude varied inversely with the height of the initial diastolic wave; the $A$ wave height exceeded the $D$ wave in patients with severe mitral stenosis. ${ }^{14)}$

The present study, using a noninvasive technique, is consistent with mild mitral prosthetic valve obstruction in a group of patients with a clinically uncomplicated mitral porcine bioprosthesis. Abnormalities of the diastolic flow profile were observed in all of our patients. These include: 1) mildly reduced slope of the ascending segment; 2) delay in the peak diastolic flow; and 3 ) presence of indentations on the descending and mid-segments of the diastolic wave. These data indicate that this bioprosthesis produces a mild restriction of diastolic filling of the left ventricle. Flow patterns consistent with severe organic mitral stenosis were not observed. ${ }^{13), 14}$ )

Diastolic flow extending into end-diastole and continuing through electrical systole during short cardiac cycles suggests a delay in mitral valve closure as a results of a pandiastolic pressure gradient during abbreviated diastolic cycles. The mitral valve remains open at end-diastole and the left ventricle continues to fill during electrical systole until left ventricular pressure exceeds that in the left atrium. ${ }^{15)}$

The abnormalities of the diastolic flow profile may be due to the reduced orifice size and/or the physical properties of the stented bioprosthesis. ${ }^{1)-5), 16)-18 \text { ) }}$ Taylor and Whamond ${ }^{18)}$ explained these altered flow dynamics by the following mechanisms: 1) delayed initial diastolic opening of the valve cusps and a decrease in the rate of acceleration of the flow; 2) increasing stiffness of the bioprosthesis during diastolic filling; and 3) turbulent flow secondary to high rates of 'shear' and high mean Reynolds numbers.

Results of several studies indicate that the qualitative patterns of velocity and flow across the currently available heart valve prostheses are similar to the stenotic mitral valve. ${ }^{16)-18)}$ Considerable hemodynamic data are available documenting modest transvalvular gradients and a mildly reduced effective valve orifice area of the mitral porcine bioprosthesis in patients with normal prosthetic function and a satisfactory postoperative New York Heart Associa- 
tion functional class. ${ }^{1-5)}$ The mean resting gradients ranged between 4.5 to $7.9 \mathrm{mmHg},{ }^{1)-5)}$ with calculated valve areas of 1.84 to $3.39 \mathrm{~cm}^{2}{ }^{2)-5}$ ) These hemodynamic studies concur with the results of flow vclocity analysis, and compare favorably with the mechanical prostheses in the mitral position. ${ }^{16)-18}$ )

In conclusion, this study demonstrates that the clinically uncomplicated porcine bioprosthesis in the mitral position results in a flow profile consistent with mild restriction to diastolic filling of the left ventricle. The transprosthetic flow pattern obtained by pulsed Doppler echocardiography resembles mild mitral stenosis. A reduced orifice size and the physical properties of the stented porcine bioprosthesis are the likely explanations for the altered blood flow patterns.

\section{REFERENGES}

1. Reis RL, Hancock WD, Yarbrough JW, Glancy DL, Morrow AG: The flexible stent. A new concept in the fabrication of tissue heart valves prostheses. J Thorac Cardiovasc Surg 62: 683,1971

2. Johnson AD, Daily PO, Peterson KL, LeWinter M, DiDonna GJ, Blair G, Niwayama G: Functional evaluation of the porcine heterograft in the mitral position. Circulation 52 (Suppl I): I-40, 1975

3. Hannah $\mathbf{H}, \mathbf{R c i s} \mathrm{RL}$ : Current status of porcine heterograft prostheses. A 5 year appraisal (abstr). Circulation 52 (Suppl II): II-30, 1975

4. MCIntosh CL, Michaelis LL, Morrow AG, Itscoitz SB, Redwood DR, Epstein SE: Atrioventricular valve replacement with the Hancock porcine xenograft. A five-year clinical experience. Surgery 78: 768, 1975

5. Lurie AJ, Miller RR, Maxwell KS, Grehl TM, Vismara LA, Hurley EJ, Mason DT: Hemodynamic assessment of the glutaraldehyde-preserved porcine heterograft in the aortic and mitral positions. Circulation 56 (Suppl II): II-104, 1977

6. Harston WE, Robertson RM, Friesinger GC: Echocardiographic evaluation of porcine heterograft valves in the mitral and aortic positions. Am Heart J 96: 443, 1978

7. Bloch WN, Felner JM, Wickliffe C, Symbas PN, Schlant RC: Echocardiogram of the porcine aortic bioprosthesis in the mitral position. Am J Cardiol 38: 293, 1976

8. Schapiro JN, Martin RP, Fowles RE, et al: Two-dimensional echocardiographic assessment of patients with bioprosthetic valves. Am J Cardiol 43: 510, 1979

9. Popp RL: Echocardiographic evaluation of left ventricular function. New Engl J Med 296: 856, 1972

10. Desser KB, Benchimol A: Blood flow velocity measured at the mitral valve of man. Am J Cardiol 33: 541, 1974

11. Kalmanson D, Bernier A, Veyrat C, Witchitz S, Savier CH, Chiche P: Normal pattern and physiological significance of mitral valve flow velocity recorded using transseptal directional Doppler ultrasound catheterization. Brit Heart J 37: 249, 1975

12. Lorch G, Rubenstein S, Baker D, Dooley T, Dodge H: Doppler echocardiography: use of a graphical display system. Circulation 56: 576, 1977

13. Kalmanson D, Veyrat F, Bouchareine F, Degroote A: Non-invasive recordings of mitral valve flow velocity patterns using pulsed Doppler echocardiography: application to diagnosis and evaluation of mitral valve disease. Brit Heart J 39: 517, 1977

14. Kalmanson D, Veyrat G, Bernier A, Witchitz S: Flow velocity tracings in patients with mitral valve disease. Diagnostic use of the transseptal Doppler catheterization. in The Mitral 
Valve. A Pluridisciplinary Approach, ed by Kalmanson D, Publishing Sciences Group, Inc, Acton, Massachusetts, p 213, 1976

15. Criley MJ, Chambers RD, Blaufuss AH, Friedman NJ: Mitral stenosis. Mechanico-acoustical events. in Physiological Principles of Heart Sounds, American Heart Association Monograph No 46, p 149-159, 1975

16. Wright JIM, Temple LJ: Relationship between the physical size, incompetence, and stenosis of prosthetic mitral valve. Thorax 27: 287, 1972

17. Folts JD, Young WP, Rowe GG: Phasic flow through normal and prosthetic mitral valves in unanesthetized dogs. J Thorac Cardiovasc Surg 61 : 235, 1971

18. Taylor DEM, Whamond JS: Velocity profiles and impedance of prosthetic mitral valves. in The Mitral Valve. A Pluridisciplinary Approach. Proceedings of the lst International Symposium on the Mitral Valve, ed by Kalmanson D, Edward Arnold, Ltd, London, p 261, 1976 